\title{
THE EFFECT OF ESTROGEN ON WATER AND ELECTROLYTE METABOLISM. I. THE NORMAL
}

\author{
By JOHN R. K. PREEDY AND ELSIE H. AITKEN
}

\author{
(From the Medical Unit, The London Hospital, London, E. 1, England)
}

(Submitted for publication August 29, 1955; accepted December 28, 1955)

The possibility that estrogens might under certain circumstances influence water and electrolyte metabolism is suggested by several observations. For instance, estrogens are related chemically to the strongly sodium-retaining steroid desoxycorticosterone (1); the recurrent ankle edema observed in some women before menstruation was considered by Fluhmann (2) to be associated with an increase in blood estrogen levels; and the edema frequently found in late pregnancy occurs at a time when estrogen production is at its height (3).

These considerations led several workers to attempt to establish a direct relationship between water and salt retention on the one hand, and estrogenic activity on the other. Thorn and Engel (4) found sodium, chloride and water retention after a single injection of estrogen into male dogs. Later, the same group of workers (5), in a study of premenstrual fluid retention, found that decreased urinary excretion of salt and water was in two patients associated with an increased output of estrogenic material in the urine. Knowlton, Kenyon, Sandiford, Lotwin, and Fricker (6) found diminished urinary excretion of sodium following the daily administration of estradiol in one normal woman, but Sharpey-Schafer and Schrire (7), using twice the amount of estradiol in ten women, found no alteration in urinary volume.

As part of an investigation into the possible role of estrogens in the fluid retention of liver disease it became necessary to establish the effect of continued estrogen administration on water and electrolyte metabolism in the normal. Water and electrolyte balance studies were therefore carried out in eleven normal subjects, and the effect of daily administration of estrogen observed.

\section{PROCEDURE}

Eleven subjects without evidence of cardiac, hepatic, renal or other disease likely to affect water and electrolyte metabolism, were selected from the wards of The London Hospital. Five subjects were under treatment for peptic ulcer, during which time no medication other than magnesium trisilicate or aluminum hydroxide was given. Two subjects had sciatic nerve pain, one osteoarthritis of the hip, one torn medial meniscus of the knee, one hallux valgus, and in one a tuberculous pleural effusion had subsided three weeks previously.

Each subject underwent a water and electrolyte balance study, lasting approximately two weeks and divided into two periods-the first a "control period," and the second an "estrogen period," during which daily injections of estrogen were given. The subjects were given a normal diet, gauged in amount and composition to individual appetite, and remaining constant throughout the study in respect of $\mathrm{Cl}, \mathrm{Na}, \mathrm{K}, \mathrm{PO}_{4}$, water and calorie content. Diet composition was calculated from appropriate tables (8). Sample dietary analyses were not carried out. The balance diet was commenced 2 to 3 days before any observations were made. Since this diet corresponded closely in composition to previous intake in each case, no longer period for metabolic adjustment was considered necessary. In all subjects daily urinary output of water, $\mathrm{Na}$ and $\mathrm{Cl}$ was estimated. In eight subjects daily urinary $\mathrm{K}$ output and in six subjects daily urinary $\mathrm{PO}_{4}$ output were measured. Fecal output of electrolytes and water were not determined. "Water balance" (Table I) was calculated by subtracting urinary volume from total water intake. Eight subjects were weighed daily in the fasting state, and in the same clothes. Cases 7, 20 and 21 were confined to bed, and weighing was not possible.

Blood analyses. Plasma concentrations of $\mathrm{Cl}$ and $\mathrm{Na}$, the total serum protein and the venous hematocrit were determined on two separate days during the control period, and again on two separate days at the end of the estrogen period.

Extracellular fluid volume. In eight subjects an estimate of changes in extracellular fluid volume was obtained by determining the volume of distribution of a known quantity of thiocyanate. Exactly $20 \mathrm{ml}$. 4 per cent $\mathrm{w} / \mathrm{v} \mathrm{NaCNS}$ was injected intravenously, no food or drink having been taken for the previous twelve hours. Plasma samples were collected four and six hours later, and their thiocyanate concentration estimated. "Thiocyanate space" was calculated by linear extrapolation of these values to zero time. The space was estimated twice on separate days both during the control period and again at the end of the estrogen period. ( $\mathrm{Na}$ injected for these determinations, about $10 \mathrm{mEq}$., was in addition to dietary $\mathrm{Na}$ intake).

Water tolerance test. After emptying the bladder, one liter of tap water was drunk in twenty minutes, no food 
or drink having been taken for the previous twelve hours. The bladder was then emptied hourly for four hours, and the volume of urine measured. Two tests were carried out in the control period, and two at the end of the estrogen period, on separate days.

Estrogen. During the estrogen period, estradiol monobenzoate $10 \mathrm{mg}$. in oil was injected intramuscularly daily. This was equivalent to between 0.14 and $0.20 \mathrm{mg}$. per $\mathbf{k g}$. body weight.

Chemical methods. Heparinized plasma was used for all determinations of plasma $\mathrm{Na}, \mathrm{Cl}$ and $\mathrm{CNS}$. Serum was used for total protein determinations. Plasma and urinary $\mathrm{Na}$, and urinary $\mathrm{K}$ were estimated by the flame photometer of Holliday and Preedy (9), except in case 4 where the plasma and urine $\mathrm{Na}$ were estimated chemically as described by Aitken and Preedy (10). Plasma and urinary $\mathrm{Cl}$ was estimated by the method of Schales and Schales (11), urinary $P$ by the method of Youngburg and Youngburg (12), total serum protein by the Kjeldahl method (13) and plasma CNS by the method of Bowler (14). The venous hematocrit was obtained by spinning heparinized blood in $10-\mathrm{cm}$. Wintrobe tubes for $20 \mathrm{~min}$ utes at 3,000 r.p.m., radius $15 \mathrm{~cm}$.

Statistical analysis. Where daily measurements were obtained (i.e., weight, water balance, urinary outputs of $\mathrm{Cl}, \mathrm{Na}, \mathrm{K}, \mathrm{PO}_{4}$ ), both individual cases and the group as a whole were statistically analyzed. Significant differences between mean values for control and estrogen periods were estimated by application of the $t$ test, a value for $P$ of 0.02 or less being taken as critical both here and in all succeeding tests. The significance of group mean differences between control and estrogen period means $(\bar{d})$ was similarly estimated.

Where less frequent observations were made (i.e., plasma determinations of $\mathrm{Cl}, \mathrm{Na}$, serum protein, venous hematocrit, thiocyanate space) group analysis only was undertaken, the significance of group mean differences (d) being estimated by the $t$ test as above.

Weight measurements in cases 43 and 44 could not be so analyzed due to a steady gain in weight during both control and estrogen periods. Regression lines for both periods were therefore constructed. The significance of differences between control and estrogen regression lines were estimated by the $t$ test.

\section{RESULTS}

Measurements of weight, "water balance," and urinary outputs of $\mathrm{Na}, \mathrm{Cl}, \mathrm{K}, \mathrm{PO}_{4}$ were obtained daily. Mean values for control and estrogen periods derived from these daily observations are given in Table I. Figures in brackets under each pair of means indicate the probability $(P)$ that the difference between these means could have been due to chance. As "water balance" denotes the figure obtained when daily urinary volume is subtracted from total daily water intake, an increase in this figure implies retention of water.
Measurements of serum protein, venous hematocrit and thiocyanate space appear only in Table I, the figures representing means of two, or occasionally three, observations on separate days.

At the foot of Table I are given the group mean differences $(\bar{d})$ between control and estrogen periods for each class of observation (e.g., urinary output of $\mathrm{Cl}, \mathrm{K}$, etc.) for the whole group, together with the value for $\mathrm{P}$.

Weight. Group mean difference (without cases 43 and 44 ) was $+0.28 \mathrm{~kg}$., $P=0.1$, indicating no significant variation following the administration of estrogen. However, analysis of individual cases shows that there was in fact a small but statistically significant mean rise in weight in Nos. 4,13 , and 45 during the estrogen period. In addition, there was a significant alteration of the regression line slope in No. 44 , indicating an increased rate of weight gain.

Water balance. No significant difference between control and estrogen periods was observed. Neither the group means nor the means in any of the eleven cases showed any significant change.

Urinary outputs. Chloride and sodium. Group $\mathrm{Cl}$ and $\mathrm{Na}$ means did not differ significantly between periods. There was no significant difference between means in any individual case, with the exception of No. 13, where the mean daily output of $\mathrm{Cl}$ increased by $36 \mathrm{mEq}$. $(\mathrm{P}=0.02)$, but without any significant change in mean $\mathrm{Na}$ output.

Potassium. There was no significant difference between group means. Differences between means in the eight individual cases in which this measurement was made were likewise non-significant.

Phosphate. The was no significant difference between group means. However, in two cases out of the six in which this estimation was made (Nos. 21 and 76), there was a mean daily decrease in phosphate output of 13 and $17 \mathrm{mEq}$. respectively. These differences were significant $(P=$ 0.01 ). In the remaining four cases the differences were non-significant.

Total serum protein level. No significant decrease in the group mean serum protein value was observed following the administration of estrogen $(\bar{d}=-0.26 \mathrm{~g}$. per $100 \mathrm{ml}$., $\mathrm{P}=0.1)$. This estimation was done in seven cases.

Venous hematocrit. There was a significant decrease in the volume of packed cells, mean difference between control and estrogen period -2.8 
ESTROGEN AND ELECTROLYTE METABOLISM-THE NORMAL

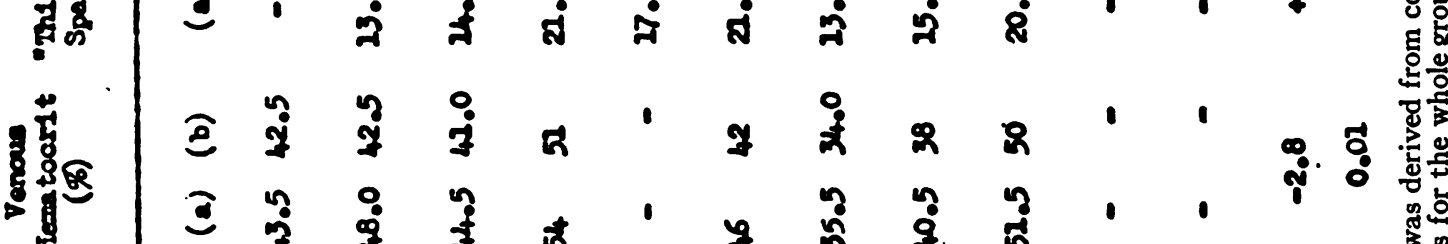

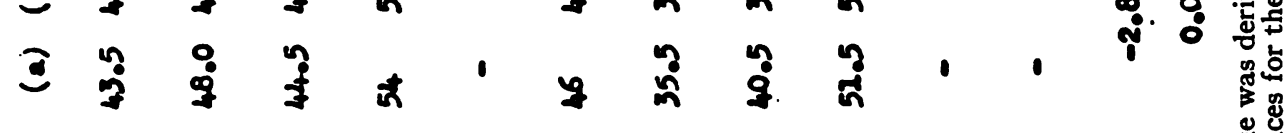

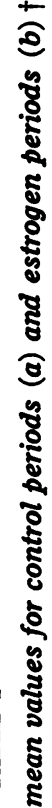

ตैं

ᄀํㅕㄴ

色

อ 1 ก, 1 ถ

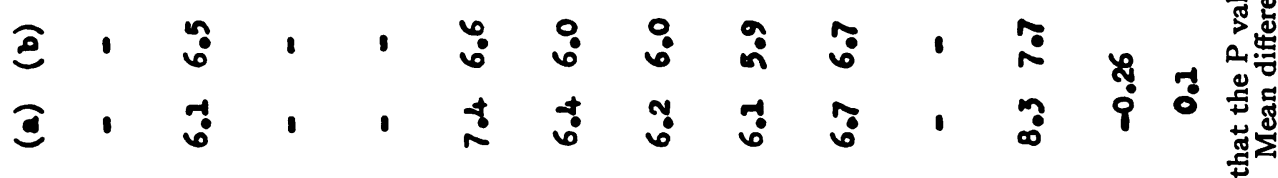

(⿻)

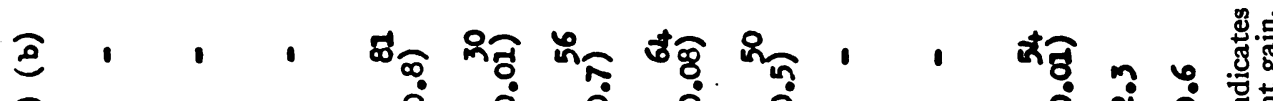

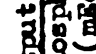

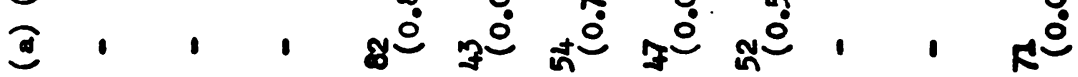

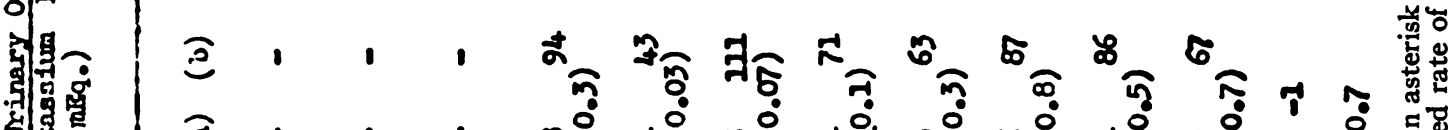

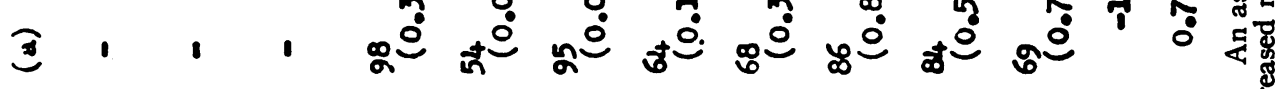

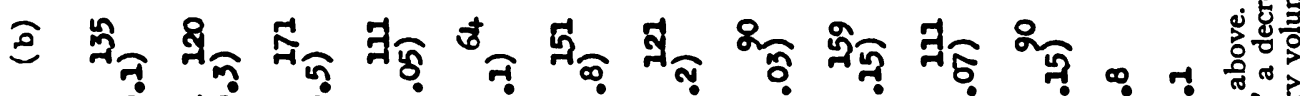

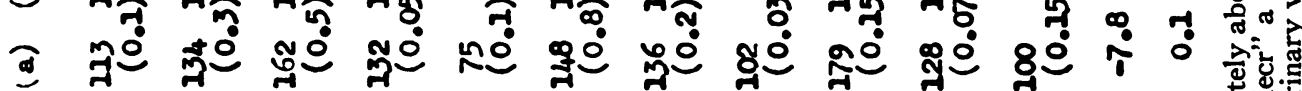

影

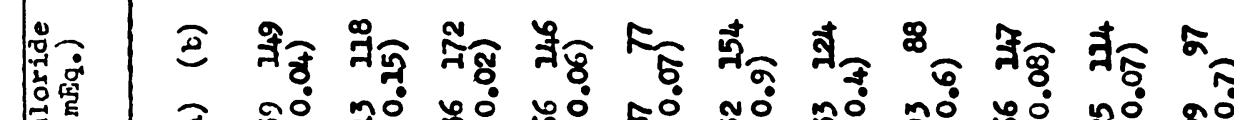

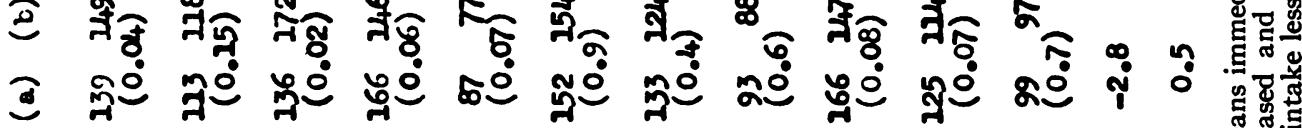

ह

丞

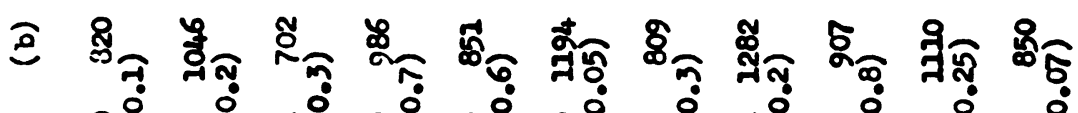

๔

8.

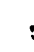

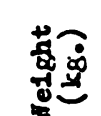

a 1 , n 1,1 i n t

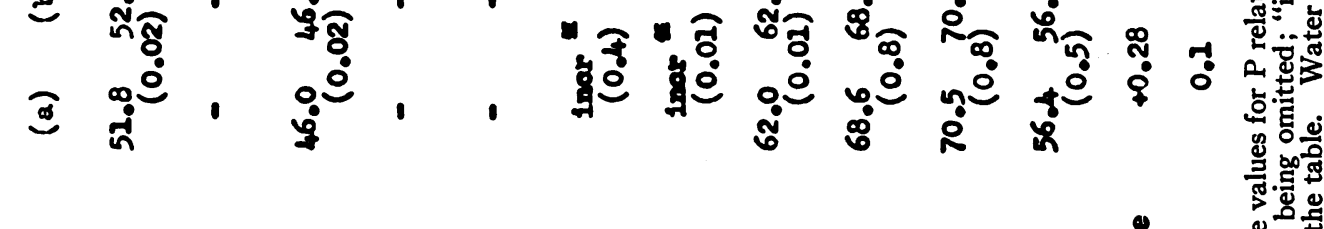

| 
TABLE II

Water tolerance tests

Hourly urinary volume in ml. in (a) control period, (b) estrogen period. Each figure represents the mean of two or three tests on alternate days. $\bar{d}=$ group mean difference. $\quad P=$ probability derived from $t$ test

\begin{tabular}{|c|c|c|c|c|c|c|c|c|c|c|}
\hline \multirow{2}{*}{$\begin{array}{l}\text { Case } \\
\text { No. }\end{array}$} & \multirow[b]{2}{*}{ Subject } & \multicolumn{2}{|c|}{ 1st Hour } & \multicolumn{2}{|c|}{ 2nd Hour } & \multicolumn{2}{|c|}{ 3rd Hour } & \multicolumn{2}{|c|}{ 4th Hour } & \multirow{2}{*}{$\begin{array}{l}\text { All hours } \\
\text { All cases }\end{array}$} \\
\hline & & (a) & (b) & (a) & (b) & (a) & (b) & (a) & (b) & \\
\hline \multirow[t]{2}{*}{$\begin{array}{r}4 \\
7 \\
13 \\
20 \\
21\end{array}$} & $\begin{array}{l}\text { H. L. } \\
\text { P. D. } \\
\text { A. W. } \\
\text { W. D. } \\
\text { E. E. }\end{array}$ & $\begin{array}{r}126 \\
303 \\
85 \\
145 \\
95\end{array}$ & $\begin{array}{r}290 \\
328 \\
55 \\
288 \\
200\end{array}$ & $\begin{array}{r}605 \\
298 \\
75 \\
460 \\
280\end{array}$ & $\begin{array}{r}488 \\
188 \\
75 \\
450 \\
210\end{array}$ & $\begin{array}{r}327 \\
650 \\
47 \\
175 \\
175\end{array}$ & $\begin{array}{r}278 \\
615 \\
775 \\
235 \\
95\end{array}$ & $\begin{array}{r}114 \\
115 \\
120 \\
60 \\
135\end{array}$ & $\begin{array}{r}150 \\
120 \\
95 \\
63 \\
65\end{array}$ & \\
\hline & & \multicolumn{2}{|c|}{$\begin{array}{r}+87 \\
0.3\end{array}$} & \multicolumn{2}{|c|}{$\begin{array}{r}-62 \\
0.3\end{array}$} & \multicolumn{2}{|c|}{$\begin{array}{r}-15 \\
0.8\end{array}$} & \multicolumn{2}{|c|}{$\begin{array}{r}-11 \\
0.9\end{array}$} & $<0.9$ \\
\hline
\end{tabular}

per cent, $P=0.01$. This estimation was done in eight cases.

"Thiocyanate space." The difference observed between the control and estrogen period group means of the eight cases in which this estimation was made was of borderline significance $(\bar{d}=+$ 0.83 L., $\mathrm{P}=0.06$ ).

Plasma chloride and sodium levels. These observations are not included in Table I. No significant difference between control and estrogen periods was observed ( $\bar{d}=0 \mathrm{mEq}$. per L., $P=$ $1, \bar{d}=-0.3 \mathrm{mEq}$. per L., $\mathrm{P}=0.9$, respectively).
Water tolerance tests. Details of the four hourly urinary volumes are given in Table II. Each figure represents the mean of two tests carried out on separate days. The tests were performed in five subjects. Mean differences for each hourly output between control and estrogen periods varied between +87 and $-62 \mathrm{ml}$., none of which was significant. Mean difference for all hours and all cases was likewise non-significant.

For each subject daily urinary output figures for $\mathrm{Cl}$ and $\mathrm{Na}$, together with those for water balance, were expressed as a percentage of the control pe-

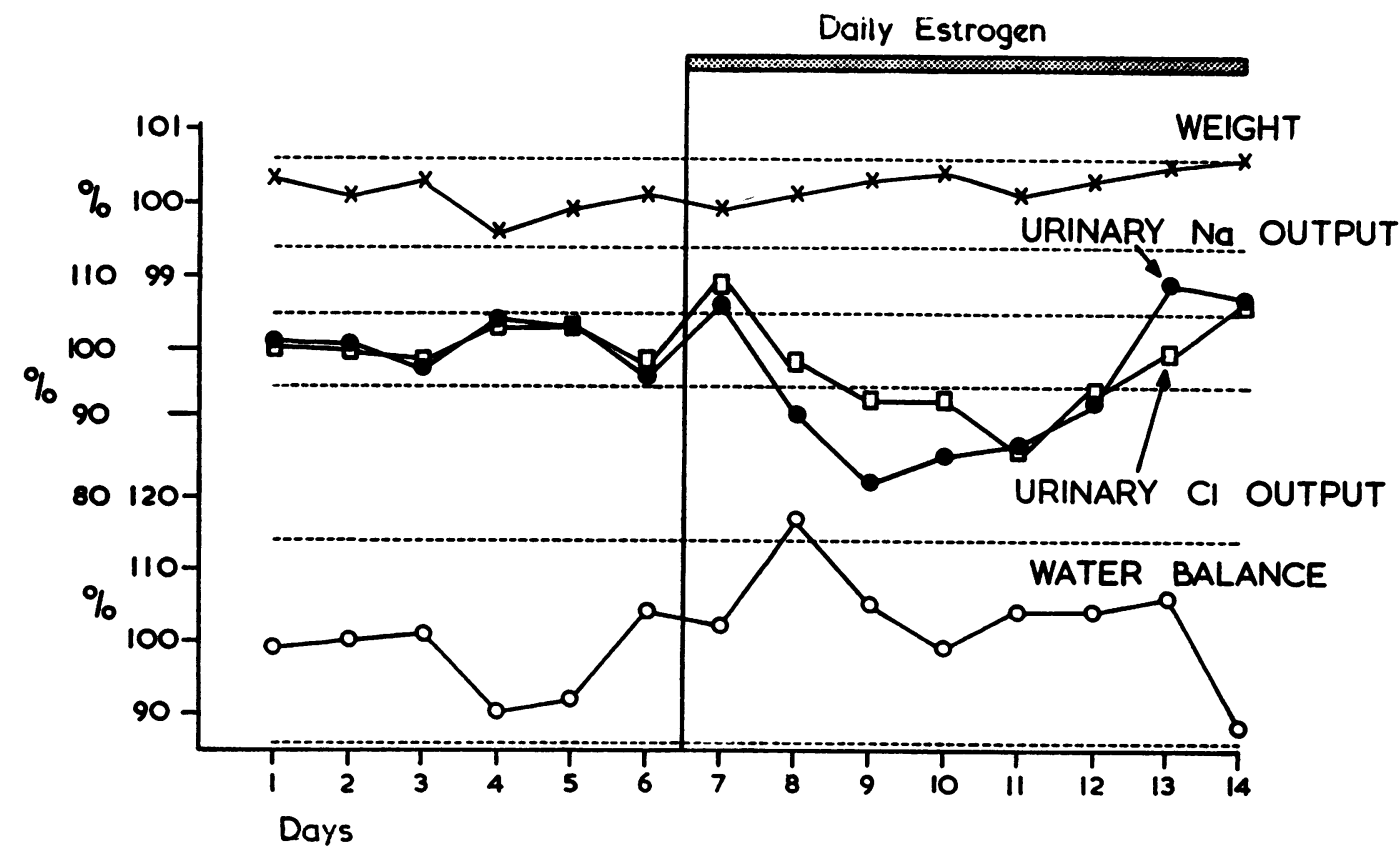

Fig. 1. The Effect of Daily Estrogen Administration on Weight, Urinary Cl and Na OUtput and Water Balance (Total Water Intake Less Urinary OUtput) in the Normal

Control period: days 1 to 6, estrogen period: days 7 to 14 . Each point represents the daily average for the group expressed as a percentage of the control period mean. Horizontal dotted lines denote 95 per cent confidence limits for the control period for each class of observation. 


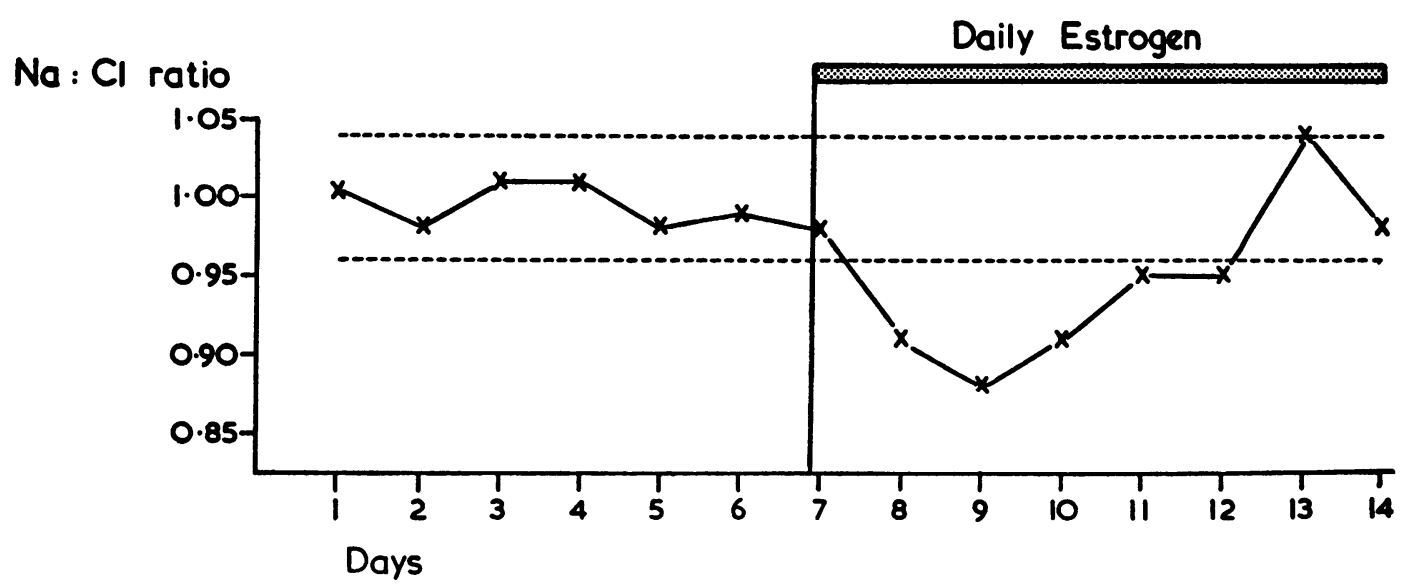

Fig. 2. The Effect of Daily Estrogen Administration on Urinary Na: Cl Ratio in the Normal Control period: days 1 to 6, estrogen period: days 7 to 14 . Each point represents the daily average for the group. Horizontal dotted lines denote 95 per cent confidence limits for the control period.

riod mean for that subject. The percentages for corresponding days were then averaged for all subjects and plotted graphically against days in Figure 1. Daily weights (cases $4,13,45,55,74$, 76) were similarly treated. For convenience figures for the last six days only of the control period appear in the graphs.

Inspection of Figure 1 shows that following the administration of estrogen there was a systematic fall in $\mathrm{Cl}$ and $\mathrm{Na}$ output during the first four days, followed by a rise in the control level or above in the last four days. This was associated with a similar but inverse variation in water balance. That the water and electrolyte changes were closely related is shown by a $\mathrm{Na}$ /water balance correlation coefficient of $0.90, \mathrm{P}=0.001$. Weight showed a slight tendency to rise after estrogen administration.

In Figure 2, the average daily urinary $\mathrm{Na}: \mathrm{Cl}$ ratios for the group were plotted against days. There was a fall in the ratio, followed by a rise to control levels or above, during the estrogen period corresponding in time to the $\mathrm{Na}$ and $\mathrm{Cl}$ variations seen in Figure 1.

The statistical significance of these variations in $\mathrm{Cl}$ and $\mathrm{Na}$ output is indicated by the presence of at least four consecutive points below the 95 per cent confidence limits in Figures 1 and 2. As regards the weight observations, although the mean value in any one day did not lie outside the 95 per cent confidence limits, the fact that the last seven points in the estrogen period were above the control mean has a probability of occurring by chance of only $(1 / 2)^{7}$, or $1: 128$. The highly significant negative correlation between $\mathrm{Na}$ output and water balance already mentioned, indicates that the variation observed in the latter was also significant.

Calculation of the cumulative balance of $\mathrm{Cl}, \mathrm{Na}$ and water during the estrogen period (taking the mean of the control period as indicating the average output of each substance at equilibrium on the diet taken) showed that there was an average positive balance of $\mathrm{Cl}$ at the end of the estrogen period amounting to $20 \mathrm{mEq}$., and of $\mathrm{Na}$ amounting to $33 \mathrm{mEq}$. The $\mathrm{Na}: \mathrm{Cl}$ ratio of these figures of $1: 0.6$ is that which would be expected, if all $\mathrm{Cl}$ and $\mathrm{Na}$ apparently retained had been stored as extracellular fluid (ECF). Calculated cumulative balance of water, however, appeared to indicate no change between periods, average balance figure at the end of the estrogen period being +43 ml. only.

The average weight gain at the end of the estrogen period was $0.6 \mathrm{~kg}$. (cases 43 and 44 were included by taking into account the difference between the regression lines). Of this, only $0.2 \mathrm{~kg}$. could be accounted for by increased volume of extracellular fluid, if the latter were calculated from the average retention of $\mathrm{Cl}$ and $\mathrm{Na}$ given above.

\section{DISCUSSION}

Statistical analysis of the group as a whole (Table I) failed to show that estradiol administra- 
tion had any sustained effect on weight, or on the urinary output of water, $\mathrm{Na}$ or $\mathrm{Cl}$. However, although no sustained alteration in urinary $\mathrm{Na}$ and $\mathrm{Cl}$ output was found, the presence of a systematic variation in the output of these substances during the estrogen period is clearly demonstrated in Figure 1. Since dietary $\mathrm{NaCl}$ intake remained constant, and assuming no significant change in fecal excretion of these ions, the findings indicate that estrogen caused a limited storage of $\mathrm{Na}$ and $\mathrm{Cl}$ followed by a diuresis while injections were still being continued.

It appears that this $\mathrm{NaCl}$ storage occurred in association with an increase in extracellular fluid (ECF) volume, since there was no change in plasma $\mathrm{Na}$ and $\mathrm{Cl}$ concentrations, there was an increase in weight, and there were corresponding changes in water balance (Figure 1). There was in addition a significant decrease and increase in urinary $\mathrm{Na}: \mathrm{Cl}$ ratio (Figure 2). The $\mathrm{NaCl}$ contents of a normal diet are roughly equivalent. This was reflected in the present series by an average urinary $\mathrm{Na}: \mathrm{Cl}$ ratio of approximately $1: 1$ during the control period. Any increase in ECF volume under these conditions must be accompanied by a decrease in urinary $\mathrm{Na}: \mathrm{Cl}$ ratio, such as is observed here.

Further evidence for an expansion of ECF is provided by the average increase in thiocyanate space, although this increase was of borderline significance only. The thiocyanate method for estimating ECF volume is open to various objections (15-17) (in common with many other methods), but is probably adequate when used to detect changes in the same subject under the conditions of the present study.

The diminution in serum protein concentration and venous hematocrit by almost the same percentage of the control mean (4.0 and 6.2, respectively) suggests a common influencing factor, that is, an increase in plasma volume of about 5 per cent. This is in agreement with the findings of other workers. Increased plasma volume has been found in both animals (18) and humans (19) after the injection of estradiol. It would appear, therefore, that the intravascular compartment takes part in the expansion of ECF following estradiol administration.

It is not certain that the observed increases in weight following estrogen can be entirely ac- counted for by an increase in ECF volume. The average cumulative balance figures, and those in some individual subjects, suggest that the weight increases may have been due in part to some other factor. This factor may be an increase in tissue formation, since estrogens have known anabolic properties (20).

The significant decrease in urinary $\mathrm{PO}_{4}$ output after estrogen, observed in cases 21 and 76 might be accounted for by retention of $\mathrm{PO}_{4}$ as part of the process of increased tissue formation. However, it seems more likely that $\mathrm{PO}_{4}$ was retained in association with $\mathrm{Ca}$, since Albright and Reifenstein (21) have shown that a positive calcium and phosphorus balance may be induced in patients with osteoporosis by estradiol administration. It is noteworthy that both our cases had a limb immobilized in plaster.

The absence of change in the result of water tolerance tests after estrogen is to be expected, since the tendency to store $\mathrm{NaCl}$ after estrogen administration in these subjects was both slight and transient, and daily urinary volume was not affected to any great degree.

Our results are in general agreement with those of Thorn and Engel (4) in dogs, and extend the observations of Knowlton, Kenyon, Sandiford, Lotwin, and Fricker (6) on one normal woman. The failure of Sharpey-Schafer and Schrire (7), using the same dosage of estradiol as ourselves, to find any alteration in urinary volume in their subjects was presumably due to the small changes involved. Urinary $\mathrm{Na}$ and $\mathrm{Cl}$ outputs (a more sensitive index) were not determined by them. However, Shapiro (22), using four to five times the dose of estradiol in normals, did observe a marked decrease in urinary volume followed by a diuresis on cessation of the estrogen. The difference between these results is presumably due to the dose employed.

The mode of action of estradiol in retaining salt and water is uncertain. The absence of any significant effect on urinary $K$ excretion in dogs (4) or in man in the present series suggests that the action may not be via the adrenals. Moreover, Thorn and Engel (4) found that adrenalectomy did not affect the salt-retaining effect of estrogen in their dogs. The action of estradiol may therefore be directly in the kidney. Since it has been shown (23) that administered estradiol does not 
affect the renal clearances of mannitol or of paraamino-hippuric acid, a direct action on the renal tubules may be involved.

\section{SUMMARY}

1. The effect of daily administration of estradiol on water and electrolyte metabolism has been studied in a group of 11 normal subjects.

2. A slight and transient decrease in urinary output of $\mathrm{Cl}, \mathrm{Na}$ and water was observed, which was significant.

3. Plasma $\mathrm{Cl}$ and $\mathrm{Na}$ levels were not significantly affected.

4. There was no significant change in urinary $K$ output in any of eight cases.

5. Urinary $\mathrm{PO}_{4}$ output was not significantly changed in 4 out of 6 cases. In the two remaining cases, there was a small but significant decrease.

6. There was a decrease in total serum protein and venous hematocrit by approximately the same percentage amount, suggesting an increase in plasma volume.

7. Evidence is presented that the transient decrease in urinary $\mathrm{Cl}, \mathrm{Na}$ and water output is associated with an increase in extracellular fluid volume.

\section{REFERENCES}

1. Heard, R. D. H., Chemistry and metabolism of the adrenal cortical hormones in The Hormones, Pincus, G., and Thimann, K. V., Eds., New York, Academic Press Inc., 1948, Vol. 1, p. 549.

2. Fluhmann, C. F., A new procedure for the determination of estrin in the blood of women. Endocrinology, 1934, 18, 705.

3. Hoffman, J., Female Endocrinology. Philadelphia, W. B. Saunders Co., 1944, Chap. 40, p. 681.

4. Thorn, G. W., and Engel, L. L., The effect of sex hormones on the renal excretion of electrolytes. J. Exper. Med., 1938, 68, 299.

5. Thorn, G. W., Nelson, K. R., and Thorn, D. W., A study of the mechanism of edema associated with menstruation. Endocrinology, 1938, 22, 155.

6. Knowlton, K., Kenyon, A. T., Sandiford, I., Lotwin, G., and Fricker, R., Comparative study of metabolic effects of estradiol benzoate and testosterone propionate in man. J. Clin. Endocrinol., 1942, 2, 671.

7. Sharpey-Schafer, E. P., and Schrire, I., The effect of cestrogens on the urinary volume. Lancet, 1939, 2, 973 .
8. McCance, R. A., and Widdowson, E. M., The chemical composition of foods. Medical Research Council, Spec. Rep. Series No. 235, London, 1940.

9. Holliday, E. R., and Preedy, J. R. K., The precision of a direct-reading flame photometer for the determination of sodium and potassium in biological fluids. Biochem. J., 1953, 55, 214.

10. Aitken, E. H., and Preedy, J. R. K., The presence of potassium as a source of inaccuracy in the chemical estimation of sodium in urine. Biochem. J., 1953, 55, 211.

11. Schales, O., and Schales, S. S., A simple and accurate method for the determination of chloride in biological fluid. J. Biol. Chem., 1941, 140, 879.

12. Youngburg, G. E., and Youngburg, M. V., Phosphorus metabolism. I. A system of blood phosphorus analysis. J. Lab. \& Clin. Med., 1930, $16,158$.

13. Hoch, H., and Marrack, J., Estimation of serum proteins. Brit. Med. J., 1945, 2, 151.

14. Bowler, R. G., The determination of thiocyanate in blood serum. Biochem. J., 1944, 38, 385.

15. Scheinberg, I. H., and Kowalski, H. J., The binding of thiocyanate to albumin in normal human serum and defibrinated blood with reference to the determination of "thiocyanate space." J. Clin. Invest., 1950, 29, 475.

16. Winkler, A. J., Elkinton, J. R., and Eisenman, A. J., Comparison of sulphocyanate with radioactive chloride and sodium in the measurement of extracellular fluid. Am. J. Physiol., 1943, 139, 239.

17. Lavietes, P. H., Bourdillon, J., and Klinghoffer, K. A., The volume of the extracellular fluid of the body. J. Clin. Invest., 1936, 15, 261.

18. Taylor, H. M., and Sprunt, D. H., Increased resistance to viral infection as a result of increased fluid in tissues. J. Exper. Med., 1943, 78, 91.

19. Witten, C. L., and Bradbury, J. T., Hemodilution as a result of estrogen therapy. Estrogenic effects in the human female. Proc. Soc. Exper. Biol. \& Med., 1951, 78, 626.

20. Kochakian, C. D., The protein anabolic effects of steroid hormones. Vitamins and Hormones, 1946, 4, 255.

21. Albright, F., and Reifenstein, E. C., Jr., The Parathyroid Glands and Metabolic Bone Disease. Baltimore; The Williams \& Wilkins Co., 1948, pp. 150 et seq.

22. Shapiro, B. G., Control of urinary secretion by the anterior pituitary. Lancet, 1938, 2, 1457.

23. Dean, A. L., Abels, J. C., and Taylor, H. C., The effects of certain homones on the renal function of man. J. Urol., 1945, 53, 647. 